\title{
Pengaruh Publikasi Tugas Melalui STAD terhadap Kerja Sama, Kreativitas, dan Prestasi Belajar IPA
}

\author{
Dzawati Muttaqiyah $^{1} *$, Indyah Sulistyo Arty ${ }^{2}$ \\ ${ }^{1}$ MTs Negeri I Lampung Tengah, Jalan Negara No.712 Yukum Jaya, Lampung Tengah, Indonesia. \\ 2 Jurusan Pendidikan Kimia, Universitas Negeri Yogyakarta, Jalan Colombo No. 1, \\ Karangmalang, Yogyakarta 55281, Indonesia. \\ * Korespondensi Penulis. Email: dzawatimuttaqiyyah@gmail.com
}

\begin{abstract}
Abstrak
Penelitian ini bertujuan untuk mengetahui: (1) pengaruh; (2) perbedaan pengaruh; (3) strategi pembelajaran yang lebih berpengaruh antara publikasi tugas melalui STAD dan tanpa publikasi tugas melalui belajar kelompok terhadap kerja sama, kreativitas, dan prestasi belajar IPA. Jenis penelitian ini adalah quasi experiment dengan counter balance design. Populasi penelitian adalah seluruh siswa kelas VIII. Sampel sejumlah dua kelas ditentukan dengan purposive sampling. Instrumen pengumpulan data berupa observasi kerja sama, tes kreativitas, dan tes prestasi belajar IPA. Untuk mengetahui pengaruh kedua strategi pembelajaran digunakan uji one sample t-tes, uji MANOVA untuk mengetahui perbedaan pengaruh, dan uji t univariat untuk mengetahui strategi pembelajaran yang lebih berpengaruh terhadap masing-masing variabel terikat. Hasil penelitian menunjukkan: (1) publikasi tugas melalui STAD berpengaruh terhadap kerja sama, kreativitas, dan prestasi belajar IPA;(2) ada perbedaan pengaruh antara publikasi tugas melalui STAD dibandingkan tanpa publikasi tugas melalui belajar kelompok terhadap kerja sama, kreativitas, dan prestasi belajar IPA; (3) publikasi tugas melalui STAD lebih berpengaruh dibandingkan tanpa publikasi tugas melalui belajar kelompok terhadap kerja sama, kreativitas, dan prestasi belajar IPA.
\end{abstract}

Kata Kunci: publikasi tugas, STAD, kerja sama, kreativitas, prestasi belajar IPA

\section{The Influence of Task Publication Through STAD on Cooperation, Creativity and Science Learning Achievement}

\begin{abstract}
This research was aimed to find out: (1) the influence; (2) the influence difference; (3) the learning strategies that are more influential between task publication through STAD and without task publication through a group learning on cooperation, creativity, and science learning achievement. This was quasi experiment using counter balance design. This research population was all grade VIII students. Two classes were established as the sample using purposive sampling technique. The instruments for data collection were observation guidelines of cooperation, creativity tests, and a science learning achievement test. One sample t-test was used to determine the influence of both learning strategies, MANOVA test was performed to determine the influence difference between these two learning strategies, and univariate t-test to determine the learning strategies that were more influential on their respective dependent variables. The research results are as follows: (1) the task publication through STAD influences cooperation, creativity, and science learning achievement; (2) there is influence difference between task publication through STAD and without task publication through a group learning on cooperation, creativity and science learning achievement; (3) task publication through STAD is more influential than without task publication through a group learning on cooperation, creativity, and science learning achievement.
\end{abstract}

Keywords: task publication, STAD, cooperation, creativity, science learning achievement

How to Cite: Muttaqiyyah, D., \& Arty, I. (2016). Pengaruh publikasi tugas melalui STAD terhadap kerja sama, kreativitas, dan prestasi belajar IPA. Jurnal Inovasi Pendidikan IPA, 2(1), 12-23. doi:http://dx.doi.org/10.21831/jipi.v2i1.8373

Permalink/DOI: http://dx.doi.org/10.21831/jipi.v2i1.8373 



\section{Jurnal Inovasi Pendidikan IPA, 2 (1), 2016 - 13}

Dzawati Muttaqiyah, Indyah Sulistyo Arty

\section{PENDAHULUAN}

Standar kompetensi lulusan pendidikan dasar dan menengah pada kurikulum 2013 berdasarkan Permendikbud No. 54 Tahun 2013 terdiri atas tiga domain yaitu sikap, pengetahuan, dan keterampilan. Ketiga domain kurikulum 2013 tersebut perlu dinilai. Untuk itu, peneliti meneliti variabel keterampilan kerja sama, kreativitas, dan prestasi belajar IPA guna mencapai standar kompetensi lulusan pada ketiga domain tersebut. Dalam penelitian ini, peneliti mengkombinasikan pembelajaran kooperatif tipe STAD dengan publikasi tugas siswa melalui pemajangan. Sesuai pendapat Slavin (1995, p.140) dan Huda (2014, p.409) yang memberikan rekomendasi agar mengimprovisasi dan memodifikasi pembelajaran kooperatif sesuai kebutuhan.

Manusia adalah makhluk sosial yang tidak dapat hidup tanpa keterlibatan manusia lain. Kerja sama adalah kebutuhan yang sangat penting untuk kelangsungan hidup. Berdasarkan kenyataan ini, diterapkanlah suatu pembelajaran yang membiasakan siswa untuk hidup bersama, bekerja sama dalam kelompok, sehingga terbina sikap kesetiakawanan sosial melalui pembelajaran kooperatif.Definisi pembelajaran kooperatif dikemukakan Slavin (1995, p.2) "Cooperative learning refers to a variety of teaching methods in which students work in small groups to help one another learn academic content". Pembelajaran kooperatif merujuk pada berbagai macam metode pengajaran dimana para siswa bekerja dalam kelompok-kelompok kecil untuk saling membantu satu sama lain dalam mempelajari materi pelajaran. Pembelajaran kooperatif menurut Johnson, Johnson, \& Smith (1998, p.25) "Itis apedagogical technique that involvesstudents working together insmallgroups to accomplish shared learning goals and to maximize their own and each other's learning". Pembelajaran kooperatif adalah teknik pembelajaran yang melibatkansiswabekerja samadalam kelompok kecil untuk bersama menyelesaikan tujuan pembelajaran dan memaksimalkan pembelajaran mereka masing-masing. Pembelajaran kooperatif menurut Jollife (2007, p.3) "Cooperative learning requires pupils to work together in small groups to support each other to improve their own learning and that of others". Dari beberapa pendapat tersebut, menunjukkan bahwa pembelajaran kooperatif adalah pembelajaran yang berpusat pada siswa untuk bekerja sama secara terstruktur dalam kelompok kecil guna mencapai tujuan pembelajaran.

Pembelajaran kooperatif memiliki prinsip-prinsip yang membedakannya dengan metode belajar kelompok yang biasa diterapkan. Johnson, Johnson, \& Smith (1995, p.7) menyatakan prinsip pembelajaran kooperatif diantaranya: (1) positive interdependence (ketergantungan positif); (2) individual accountability (tanggung jawab individu); (3) face to face promotive interaction (tatap muka dan interaksi promotif); (4) interpersonal and small group skill (keterampilan interpersonal dan kelompok kecil) dan (5) group processing (evaluasi proses kelompok). Banyak sekali keuntungan dan alasan diterapkannya pembelajaran kooperatif. Lord (2001, p.35) meresume dari berbagai hasil penelitian tentang 101 alasan diterapkannya pembelajaran kooperatif, diantaranya bahwa pembelajaran kooperatif dapat meningkatkan siswa dalam hal: (1) berpikir dan belajar sains; (2) lingkungan belajar pada sains; (3) sikap terhadap sains; (4) prestasi dan penilaian terhadap sains;(5) pembelajaran sains; (6) kemampuan membaca dan menulis sains;(7) keterampilan sosial; (8) sains dapat diterapkan dalam kehidupan nyata; (9) mendukung baik siswa laki-laki maupun perempuan.

Salah satu tipe pembelajaran kooperatif yaitu Student Teams Achievement Division atau STAD. Tiantong \& Teemuangsai (2013, p.86) memberi definisi tentang STAD "It is a collaborative learning strategy in which small groups of learners with different levels of ability work together to accomplish a shared learning goal. STAD menurut Rei (Khan \& Inamullah (2011, p.212) "STAD is one of the many strategies in cooperative learning, which helps promote collaboration and self-regulating learning skills". STAD adalah tipe pembelajaran kooperatif yang menempatkan siswa dalam kelompok heterogen baik dari segi tingkat kinerja, jenis kelamin, maupun etnis yang beranggotakan empat hingga lima orang untuk bekerja sama dalam mencapai tujuan pembelajaran. Langkah STAD seperti diungkapkan Slavin (1995, p.71) "STAD consists of five major component-class presentations, teams, quizzes, individual improvement scores, and team recognition". STAD berisi lima komponen utama yaitupresentasi kelas, kerja kelompok, kuis, skor kemajuan individu, dan penghargaan kelompok.

Tujuan diterapkannya STAD agar seluruh siswa dapat menguasai materi pelajaran dengan saling bekerja sama bersama rekan sekelompok- 
nya. Dalam STAD siswa dituntut untuk bertanggung jawab terhadap diri mereka sendiri demi kemajuan kelompok. Khan \& Inamullah (2011, p.212) menyatakan alasan diterapkannya STAD"The reason for the selection of STAD is good interaction among students, improve positive attitude towards subject, better self-esteem, increased interpersonal skills". Alasan pemilihan STAD adalah agar tercipta interaksi positif antar siswa, meningkatkan sikap positif terhadap pelajaran, meningkatkan harga diri, meningkatkan keterampilan interpersonal, mengajarkan siswa bekerja dengan rekan-rekannya agar berhasil menguasai materi pembelajaran.

Dalam penelitian ini, pembelajaran kooperatif tipe STAD dimodifikasi dengan publikasi tugas, caranya siswa mendapatkan perlakuan pembelajaran kooperatif tipe STAD, lalu tugas individu dan hasil kerja dalam langkah kerja kelompok dipublikasikan dengan cara pemajangan. Publikasi tugas melalui pemajangan atau pameran hasil karya siswa adalah salah satu cara dalam mendokumentasikan tugas siswa. Mendokumentasikan tugas siswa menjadi sesuatu yang sangat penting. Seperti dikemukakan Helm, Beneke, \& Steinheimer (1998, p.15) "WHY DOCUMENT? Through documentation the teacher can make it possible for others to "see" the learning that takes place when developmentally appropriate teaching occurs". Melalui dokumentasi, guru dapat membuat orang lain melihat perkembangan pembelajaran. Dokumentasi dengan publikasi tugas siswa melalui pemajangan dapat memudahkan orang lain melihat pembelajaran yang sedang berlangsung. Hal ini dapat menginformasikan pembelajaran kepada orang yang melihatnya.

Watson \& Davis (2010, pp.22-23) juga menyatakan materi pelajaran dan tugas siswa yang diumumkan kepada siswa dan dipasang di dinding kelas selain mengajak siswa untuk memahami materi pelajaran, juga mengajak mereka berlatih menghubungkan satu hal dengan hal lainnya serta dapat membangun suasana kebersamaan dalam menyelesaikan pekerjaan yang penting bagi pengembangan diri siswa. Apabila setiap hari siswa melihat pajangan, itu akan memperkuat proses belajar. Jika siswa sendiri yang membuat pajangan, maka proses belajar akan dihayati oleh masing-masing siswa.

Publikasi tugas melalui pembelajaran kooperatif tipe STAD diharapkan dapat meningkatkan keterampilan kerja sama siswa. Pengertian kerja sama seperti diungkapkan oleh Montiel-Overall (Haycock, 2007, p.26)
"Collaboration is atrusting, working relationship between two or more equal participants involved in shared thinking, shared planning and shared creation of integrated instruction". Kerja sama adalah kepercayaan, hubungan kerja antara dua atau lebih peserta yang terlibat dalam pemikiran, perencanaan, dan penciptaan bersama instruksi yang terintegrasi. Kerja sama menurut Gentry (2012, p.5) yaitu "It is a frame work where by two or more individuals work together as equal partners to make decisions that willlead to positive changes". (Kerja sama adalah kerangka kerja dari dua atau lebih individu yang bekerja sama sebagai mitra setara untuk membuat keputusan yang akan membawa perubahan positif). Berdasarkan pengertian kerja sama tersebut, keterampilan kerja sama dapat dinyatakan sebagai keterampilan yang harus dimiliki dalam hubungan kerja antara dua orang siswa atau lebih yang saling membutuhkan dan melengkapi guna mencapai tujuan pembelajaran.

Menurut Lundgren, (Rusman, 2012, pp.210-211), ada tiga tingkat keterampilan kerja sama yaitu keterampilan kerja sama tingkat awal, menengah, dan mahir. Dalam penelitian ini, keterampilan kerja sama yang diteliti adalah keterampilan kerja sama tingkat awal, pengamatan dilakukan saat siswa bekerja dalam kelompoknya. Berdasarkan kemampuan kerja sama tingkat awal yang dikemukakan Lundgren (1994), peneliti mengembangkan instrumen keterampilan kerja sama menggunakan pedoman observasi. Indikator keterampilan kerja sama tingkat awal meliputi: (1) menggunakan kesepakatan; (2) menghargai kontribusi; (3) mengambil giliran dan berbagi tugas; (4) berada dalam kelompok; (5) berada dalam tugas; (6) mendorong partisipasi; (7) mengundang orang lain untuk bicara; (8) menyelesaikan tugas pada waktunya; dan (9) menghormati perbedaan individu.

Selain diharapkan dapat meningkatkan keterampilan kerja sama, publikasi tugas melalui pembelajaran kooperatif tipe STAD juga diharapkan dapat meningkatkan kreativitas siswa. Kreativitas penting dimiliki oleh siswa guna menghadapi tantangan masa depan. Seperti diungkapkan Sugiarto (2015, p.2) bahwa alasan mendasar yang mengharuskan pengajaran kreativitas adalah upaya membantu siswa dalam mempersiapkan kemungkinan yang dihadapi di kemudian hari agar memiliki alternatif penyesaian masalah yang tepat. Maker et al. (2006, p.103) juga menyatakan khususnya untuk negara timur (Korea, Cina, Hongkong, Singapura, Taiwan, dan Indonesia), kreativitas dipandang 


\section{Jurnal Inovasi Pendidikan IPA, 2 (1), 2016 - 15}

Dzawati Muttaqiyah, Indyah Sulistyo Arty

sangat penting untuk kemajuan masyarakat, sehingga pengembangan kreativitas merupakan komponen penting dalam reformasi kurikulum. Guru didorong untuk menggunakan berbagai pendekatan untuk pengembangan kreativitas pada anak disemua usia.

Pengertian kreativitas seperti yang diungkapkan Komite Penasihat Nasional untuk Kreatif dan Pendidikan Budaya di UK National Advisory Committee on Creative and Cultural Education (NACCCE); NACCCE (Joubert, 2007, p.18) bahwa "Creativity as imaginative activity fashioned so as to produce outcomes that are both original and of value". Kreativitas didefinisikan sebagai kegiatan imajinatif dibentuk sedemikian rupa sehingga memberi hasil asli dan bernilai. Kreativitas menurut Jayalekshmi \& Raja (2011, p.33)“Creativity means to make, to bring into being, to originate or to invent something". Kreativitas berarti membuat sesuatu menjadi ada atau menciptakan sesuatu. Munandar (1999, p.50) menyatakan bahwa secara operasional kreativitas dapat dirumuskan sebagai "Kemampuan yang mencerminkan kelancaran, keluwesan (fleksibilitas), dan orisinalitas dalam berpikir, serta kemampuan untuk mengelaborasi (mengembangkan, memperkaya, memperinci) suatu gagasan". Dari beberapa pendapat tersebut dapat disimpulkan bahwa kreativitas adalah suatu tindakan untuk memunculkan gagasan, metode, atau produk baru yang asli dan bernilai berdasarkan informasi yang ada yang lebih efektif, efisien, fleksibel, dan berdaya guna untuk pemecahan suatu masalah.

Guilford (Munandar, 2012, pp.10-11) menyatakan ciri-ciri utama dari kreativitas terdiri atas ciri aptitude (berpikir kreatif) dan non-aptitude (sikap kreatif). Contoh ciri nonaptitude seperti kepercayaan diri, keuletan, apresiasi estetik, serta kemandirian. Ciri aptitude seperti diungkapkan Williams (Munandar, 1999, pp.88-90) berupa mampu berpikir dengan lancar (fluency), luwes (flexibility), asli (originality, danterperinci (elaboration). Dalam penelitian ini, kreativitas diukur dengan mengembangkan ciri aptitude kreativitas yang dikemukakan Williams (1977) berupa soal uraian pada Kompetensi Dasar 3.10 (Memahami konsep getaran, gelombang, bunyi, dan pendengaran, serta penerapannya dalam sistem sonar pada hewan dan dalam kehidupan sehari-hari).

Siswa yang telah memiliki keterampilan kerja sama dan kreativitas dengan baik akan berpengaruh terhadap prestasi belajar. Slameto (2013, p.331) memberi definisi prestasi belajar
"Student's achievement are also often called achievement is a specific statement of what will be known and can be done by the students, as a result of learning, which is usually in the form of knowledge, skills, or attitudes". (Prestasi belajar yaitu sesuatu yang dapat diketahui dan dilakukan oleh siswa sebagai hasil belajar, berupa pengetahuan, keterampilan, atau sikap). Djamarah (2012, p.23) juga mengemukakan bahwa prestasi belajar adalah hasil yang diperoleh dari aktivitas belajar yang mengakibatkan perubahan dalam diri individu. Dari beberapa pengertian prestasi belajar ini, dapat disimpulkan bahwa prestasi belajar adalah hasil yang dicapai seseorang setelah mengalami proses belajar yang dinyatakan dalam nilai mata pelajaran.

Setelah mengikuti kegiatan pembelajaran, siswa diharapkan akan memperoleh prestasi belajar berupa tercapainya tujuan pembelajaran. Untuk mengetahui tercapai tidaknya tujuan pembelajaran, perlu dilakukan suatu usaha penilaian terhadap proses belajar. Alat untuk menilai proses belajar siswa salah satunya yaitu dengan tes prestasi belajar. Dengan melakukan tes prestasi belajar, maka prestasi belajar yang dicapai siswa dapat ditandai dengan skala nilai berupa angka. Dalam penelitian ini, prestasi belajar IPA siswa diukur menggunakan instrumen tes multiple choice yang dikembangkan berdasarkan Kompetensi Dasar 3.10.

Publikasi tugas melalui pemajangan dapat dijadikan alternatif dalam memfariasikan pembelajaran. Penelitian Boone (2008, pp.22-45) mengungkapkan pengalaman hidup anak-anak yang karya seninya ditampilkan atau dipajangkan menghasilkan dua belas tema penting serta implikasinya terhadap pendidikan seni anak yang dieksplorasi. Penelitian Wulandari, Fuady, \& Sumarwati (2012, pp.77-92) menunjukkan bahwa publikasi karya memotivasi siswa menulis sebaik-baiknya. Siswa menyatakan bahwa pemajangan puisi di mading sekolah menjadikan mereka lebih bersemangat untuk menulis puisi yang lebih baik, karena hasil puisi mereka akan dipajang di mading dan akan banyak orang yang membacanya, bukan hanya teman satu kelas tetapi juga siswa dari kelas lain bahkan juga guru. Berdasarkan hasil penelitian-penelitian tersebut, dapat diketahui bahwa publikasi tugas dengan pemajangan dapat meningkatkan motivasi siswa untuk menghasilkan tugas yang lebih baik lagi. Publikasi tugas siswa juga diharapkan dapat meningkatkan keterampilan kerja sama, kreativitas, dan prestasi belajar IPA siswa. 
Berdasarkan pengalaman peneliti selama mengabdi di MTs Negeri I Lampung Tengah dan berdasarkan studi pendahuluan pada 6 Agustus 2014 diketahui bahwa guru IPA telah menerapkan pembelajaran kooperatif tetapi kurang terstruktur. Pembelajaran kooperatif yang diterapkan baru sebatas pada pembelajaran kelompok biasa. Guru belum menjadikan keterampilan kerja sama dan kreativitas siswa sebagai komponen yang menjadi perhatian penting dalam pembelajaran maupun penilaian, hal ini mengakibatkan banyak siswa belum memiliki keterampilan kerja sama dengan baik. Hal ini dapat dilihat dari pembagian tugas dalam kelompok dan diskusi kelompok. Dalam mengerjakan tugas kelompok, siswa yang aktif mendominasi kelompok dan berperan besar dalam menyelesaikan tugas. Kreativitas sebagian besar siswa juga masih kurang, tampak ketika menyelesaikan tugas, siswa masih terpaku pada contoh dari guru. Akibat kurangnya keterampilan kerja sama dan kreativitas siswa, prestasi belajar IPA siswa pun menjadi kurang maksimal. Hal ini diketahui dari rata-rata nilai murni IPA kelas VIII pada ujian akhir semester genap Tahun Pelajaran 2013/2014 sebesar 40,86. Guru IPA juga belum melakukan publikasi tugas siswa. Setelah diperiksa guru, tugas siswa langsung dibagikan tanpa dipublikasikan atau dipajangkan terlebih dahulu. Pajangan yang bersifat edukatif hanya terdapat di dinding kelas dan tidak terdapat di tempat lain yang dapat mendorong siswa untuk belajar. Pajangan yang dipajang pun bukan dari hasil karya siswa sendiri tetapi dari gambar jadi yang ada di pasaran. Pajangan tidak pernah diperbaharui sesuai hasil pekerjaan siswa yang selalu berkembang. Berdasarkan permasalahan ini, peneliti tertarik menerapkan publikasi tugas melalui pembelajaran kooperatif tipe STAD di MTs Negeri I Lampung Tengah dengan variabel terikat berupa keterampilan kerja sama, kreativitas, dan prestasi belajar IPA.

Tujuan penelitian ini adalah untuk mengetahui: (1) pengaruh strategi pembelajaran publikasi tugas melalui pembelajaran kooperatif tipe STAD terhadap keterampilan kerja sama, kreativitas, dan prestasi belajar IPA; (2) perbedaan pengaruh antara strategi pembelajaran publikasi tugas melalui pembelajaran kooperatif tipe STAD dengan tanpa publikasi tugas melalui belajar kelompok terhadap keterampilan kerja sama, kreativitas, dan prestasi belajar IPA; serta (3) strategi pembelajaran yang lebih berpengaruh antara publikasi tugas melalui pembelajaran kooperatif tipe STAD dengan tanpa publikasi tugas melalui belajar kelompok terhadap keterampilan kerja sama, kreativitas, dan prestasi belajar IPA siswa kelas VIII MTs Negeri I Lampung Tengah.

\section{METODE}

\section{Jenis Penelitian}

Jenis penelitian ini adalah quasi experiment dengan counter balance design. Pada desain ini terdapat dua kelas eksperimen yaitu kelas eksperimen I dan kelas eksperimen II. Masing-masing kelas eksperimen diberi perlakuan sama dengan diterapkan secara bergantian strategi pembelajaran publikasi tugas melalui pembelajaran kooperatif tipe STAD dan tanpa publikasi tugas melalui belajar kelompok.

\section{Waktu dan Tempat Penelitian}

Penelitian ini dilakukan di MTs Negeri I Lampung Tengah Provinsi Lampung yang dilaksanakan pada bulan Februari hingga Maret 2015.

\section{Subjek Penelitian}

Sampel dalam penelitian ini adalah kelas VIII C dan VIII D masing-masing berjumlah 43 siswa yang diambil dari populasi sebanyak tujuh kelas dengan jumlah 296 siswa secara purposive sampling.

\section{Variabel Penelitian}

Variabel pada penelitian ini meliputi variabel bebas yang terdiri dari publikasi tugas melalui pembelajaran kooperatif tipe STAD dan tanpa publikasi tugas melalui belajar kelompok. Variabel terikat terdiri keterampilan kerja sama, kreativitas, dan prestasi belajar IPA.

\section{Teknik Pengumpulan Data}

Pengumpulan data menggunakan pedoman observasi keterampilan kerja sama, tes kreativitas, dan tes prestasi belajar IPA yang dilakukan baik sebelum maupun setelah perlakuan.

\section{Teknik Analisis Data}

Sebelum analisis data dilakukan,terlebih dahulu dilakukan uji persyaratan analisis berupa uji normalitas dan homogenitas data. Uji normalitas data dengan uji Kolmogorov-Smirnov (K-S). Uji homogenitas untuk mengetahui homogenitas matriks varians-kovarians menggunakan uji homogenitas Box's $M$ dan untuk mengetahui homogenitas varians dua kelompok perlakuan masing-masing variabel terikat dilakukan uji homogenitas Levene's. Setelah uji 
normalitas dan homogenitas data, dilanjutkan uji one sample t-tes untuk mengetahui pengaruh kedua strategi pembelajaran terhadap masingmasing variabel terikat, selanjutnya dilakukan uji MANOVA untuk mengetahui perbedaan pengaruh antara kedua strategi pembelajaran, dan dilanjutkan dengan uji $\mathrm{t}$ univariat untuk mengetahui strategi pembelajaran yang lebih berpengaruh terhadap masing-masing variabel terikat. Pengujian dilakukan pada taraf signifikansi $5 \%$.

\section{HASIL DAN PEMBAHASAN}

\section{Uji Persyaratan Analisis}

\section{Uji Normalitas Data}

Uji normalitas data dilakukan sebelum dan setelah perlakuan. Hasil uji normalitas data disajikan pada Tabel 1. Berdasarkan Tabel 1 terlihat bahwa hasil uji normalitas sebelum perlakuan dan setelah perlakuan untuk semua variabel terikat mempunyai nilai signifikansi $>\alpha$ $(0,05)$, yang berarti bahwa data variabel penelitian berdistribusi normal terhadap populasinya.

\section{Uji Homogenitas Data}

Hasil uji homogenitas data disajikan pada Tabel 2. Berdasarkan Tabel 2 terlihat bahwa hasil uji homogenitas matriks varians-kovarians melalui uji Box's- $M$ dan hasil uji homogenitas varians dua kelompok perlakuan masing-masing variabel terikat dilakuakan melalui uji Levene's baik sebelum maupun setelah perlakuan didapatkan nilai signifikansi $>\alpha(0,05)$. Hal ini berarti matriks varians-kovarians dan varians kelompok pembelajaran publikasi tugas melalui pembelajaran kooperatif tipe STAD dan tanpa publikasi tugas melalui belajar kelompok adalah homogen baik pada variabel keterampilan kerja sama, kreativitas, maupun prestasi belajar IPA.

\section{Hasil Uji Hipotesis Penelitian}

Hasil Uji One Sample t-Test

Uji one sample t-test digunakan untuk mengetahui pengaruh strategi pembelajaran publikasi tugas melalui pembelajaran kooperatif tipe STAD dan tanpa publikasi tugas melalui belajar kelompok terhadap keterampilan kerja sama, kreativitas, dan prestasi belajar IPA siswadan didapatkan hasil seperti Tabel 3.

Tabel 1. Uji Normalitas Sebelum dan Setelah Perlakuan

\begin{tabular}{ccccc}
\hline Kondisi & Pembelajaran & Instrumen & Sig & Kriteria \\
\hline \multirow{5}{*}{ Sebelum perlakuan } & Publikasi tugas melalui STAD & Kerja sama & 0,059 & Normal \\
& & Kreativitas & 0,072 & Normal \\
& & Prestasi & 0,2 & Normal \\
\cline { 2 - 6 } & \multirow{3}{*}{ Tanpa publikasi tugas melalui belajar kelompok } & Kerja sama & 0,059 & Normal \\
& & Kreativitas & 0,114 & Normal \\
& \multirow{3}{*}{ Setelah perlakuan } & Prestasi & 0,078 & Normal \\
\cline { 3 - 6 } & \multirow{2}{*}{ Publikasi tugas melalui STAD } & Kerja sama & 0,066 & Normal \\
& & Kreativitas & 0,097 & Normal \\
& \multirow{2}{*}{ Tanpa publikasi tugas melalui belajar kelompok } & Prestasi & 0,152 & Normal \\
\cline { 2 - 6 } & & Kerja sama & 0,069 & Normal \\
& & Kreativitas & 0,2 & Normal \\
& & Prestasi & 0,2 & Normal \\
\hline
\end{tabular}

Tabel 2. Hasil Uji Homogenitas Data

\begin{tabular}{cccccc}
\hline \multirow{2}{*}{ Kondisi } & \multicolumn{2}{c}{ Box's $\boldsymbol{M}$} & \multicolumn{3}{c}{ Levene Test } \\
\cline { 2 - 6 } & Sig & Kriteria & Variabel & Sig & Kriteria \\
\hline \multirow{3}{*}{ Sebelum perlakuan } & \multirow{2}{*}{0,086} & \multirow{2}{*}{ Homogen } & Kerja sama & 1,00 & Homogen \\
& & & Kreativitas & 0,757 & Homogen \\
& \multirow{2}{*}{0,418} & \multirow{2}{*}{ Homogen } & Prestasi & 0,895 & Homogen \\
\hline \multirow{2}{*}{ Setelah perlakua } & Kreativitas & 0,998 & Homogen \\
& & & Prestasi & 0,66 & Homogen \\
& & & & & Homogen \\
\hline
\end{tabular}


Jurnal Inovasi Pendidikan IPA, 2 (1), 2016 - 18

Dzawati Muttaqiyah, Indyah Sulistyo Arty

Tabel 3. Hasil Uji One Sample t-Test

\begin{tabular}{llcl}
\hline \multicolumn{1}{c}{ Perlakuan } & Variabel & Sig. (2-tailed) & Makna \\
\hline \multirow{2}{*}{$\begin{array}{l}\text { Publikasi tugas melalui pembelajaran } \\
\text { kooperatif tipe STAD }\end{array}$} & Kerja sama & 0,000 & Berpengaruh \\
& Kreativitas & 0,000 & Berpengaruh \\
& Prestasi belajar IPA & 0,000 & Berpengaruh \\
\hline \multirow{2}{*}{ Tanpa publikasi tugas melalui belajar kelompok } & Kerja sama & 0,468 & Tidak berpengaruh \\
& Kreativitas & 0,000 & Berpengaruh \\
& Prestasi belajar IPA & 0,000 & Berpengaruh \\
\hline
\end{tabular}

Hasil uji one sample t test pada perlakuan publikasi tugas melalui pembelajaran kooperatif tipe STAD didapatkan nilai sig $0,000<\alpha(0,05)$ untuk masing-masing variabel terikat. Hal ini berarti publikasi tugas melalui pembelajaran kooperatif tipe STAD berpengaruh terhadap ketiga variabel terikat baik keterampilan kerja sama, kreativitas, maupun prestasi belajar IPA. Hasil uji one sample $t$ testpada perlakuantanpa publikasi tugas melalui belajar kelompok didapatkan nilai sig $0,468>\alpha(0,05)$ untuk variabel keterampilan kerja sama dan sig $0,000<\alpha$ $(0,05)$ untuk variabel kreativitas dan prestasi belajar IPA. Hal ini berarti tanpa publikasi tugas melalui belajar kelompok hanya berpengaruh terhadap kreativitas dan prestasi belajar IPA dan tidak berpengaruh terhadap keterampilan kerja sama. Tidak berpengaruhnya strategi pembelajaran tanpa publikasi tugas melalui belajar kelompok terhadap keterampilan kerja sama diakibatkan karena guru sering menggunakan strategi pembelajaran ini. Guru sering membagi siswa kedalam kelompok sehingga siswa telah terbiasa bekerja sama dalam kelompok. Hal ini dapat diketahui dari hasil observasi sebelum diberikan perlakuan yang menunjukkan bahwa keterampilan kerja sama siswa telah mencapai rata-rata 65,31 yang berada pada kategori baik.

\section{Hasil Uji Multivariat (MANOVA)}

Uji multivariat dilakukan dengan Hotteling's Trace baik sebelum maupun setelah perlakuan. Uji multivariat sebelum perlakuan bertujuan untuk melihat ada tidaknya perbedaan rata-rata kemampuan keterampilan kerja sama, kreativitas, dan prestasi belajar IPA kedua kelompok sebelum perlakuan. Uji multivariat kondisi akhir bertujuan untuk mengetahui ada tidaknya perbedaan pengaruh antara publikasi tugas melalui pembelajaran kooperatif tipe STAD dan tanpa publikasi tugas melalui belajar kelompok terhadap keterampilan kerja sama, kreativitas, dan prestasi belajar IPA siswa. Hasil uji multivariat disajikan pada Tabel 4.
Tabel 4. Hasil Uji Multivariat

\begin{tabular}{ccl}
\hline Kondisi & Sig & \multicolumn{1}{c}{ Makna } \\
\hline Sebelum & 0,818 & $\begin{array}{l}\text { Tidak ada perbedaan rata-rata } \\
\text { kemampuan kerja sama, kre- } \\
\text { ativitas, dan prestasi belajar } \\
\text { IPA. }\end{array}$ \\
\hline Setelah & 0 & $\begin{array}{l}\text { Ada perbedaan pengaruh } \\
\text { kedua strategi pembelajaran } \\
\text { terhadap ketiga variabel } \\
\text { terikat. }\end{array}$ \\
\hline
\end{tabular}

Berdasarkan hasil uji multivariat sebelum perlakuan diperoleh nilai signifikansi Hotteling's Trace sebesar $0,818>\alpha(0,05)$ yang berarti bahwa tidak ada perbedaan rata-rata kemampuan kerja sama, kreativitas, dan prestasi belajar IPA siswa sebelum diterapkan strategi pembelajaran publikasi tugas melalui pembelajaran kooperatif tipe STAD dan tanpa publikasi tugas melalui belajar kelompok. Berdasarkan hasil uji multivariat setelah perlakuan diperoleh nilai signifikansi Hotteling's Trace sebesar $0,000<\alpha(0,05)$ yang berarti $\mathrm{H}_{0}$ bahwa terdapat perbedaan pengaruh antara publikasi tugas melalui pembelajaran kooperatif tipe STAD dan tanpa publikasi tugas melalui belajar kelompok terhadap keterampilan kerja sama, kreativitas, dan prestasi belajar IPA siswa.

\section{Hasil Uji t Univariat}

Berdasarkan uji multivariat setelah perlakuan diketahui bahwa terdapat perbedaan pengaruh antara publikasi tugas melalui pembelajaran kooperatif tipe STAD dan tanpa publikasi tugas melalui belajar kelompok terhadap ketiga variabel terikat, selanjutnya dilakukan uji lanjut $\mathrm{t}$ univariat dengan independent samples test untuk mengetahui strategi pembelajaran manakah yang lebih berpengaruh besar terhadap masingmasing variabel keterampilan kerja sama, kreativitas, dan prestasi belajar IPA siswa. Hasil uji independent samples test disajikan pada Tabel 5. 
Tabel 5. Hasil Uji Independent Samples Test

\begin{tabular}{lcl}
\hline Variabel & $\begin{array}{l}\text { Sig. (2- } \\
\text { tailed })\end{array}$ & \multicolumn{1}{c}{ Makna } \\
\hline Kerja sama & 0,000 & $\begin{array}{l}\text { Publikasi tugas melalui } \\
\text { pembelajaran kooperatif } \\
\text { tipe STAD lebih } \\
\text { berpengaruh }\end{array}$ \\
\hline Kreativitas & 0,000 & $\begin{array}{l}\text { Publikasi tugas melalui } \\
\text { pembelajaran kooperatif } \\
\text { tipe STAD lebih } \\
\text { berpengaruh }\end{array}$ \\
\hline $\begin{array}{l}\text { Prestasi } \\
\text { belajar IPA }\end{array}$ & 0,003 & $\begin{array}{l}\text { Publikasi tugas melalui } \\
\text { pembelajaran kooperatif } \\
\text { tipe STAD lebih } \\
\text { berpengaruh }\end{array}$ \\
\hline
\end{tabular}

Berdasarkan hasil uji independent samples test univariat untuk mengetahui strategi pembelajaran mana yang lebih berpengaruh terhadap ketiga variabel terikat didapatkan nilai sig $<\alpha$ $(0,05)$ untuk semua variabel terikat. Hal ini berarti bahwa strategi pembelajaran publikasi tugas melalui pembelajran kooperatif tipe STAD lebih berpengaruh daripada tanpa publikasi tugas melalui belajar kelompok baik terhadap keterampilan kerja sama, kreativitas, maupun prestasi belajar IPA.

Publikasi tugas melalui pembelajaran kooperatif tipe STAD lebih berpengaruh daripada tanpa publikasi tugas melalui belajar kelompok terhadap keterampilan kerja sama karena dalam pembelajaran publikasi tugas melalui pembelajaran kooperatif tipe STAD memberi kesempatan kepada siswa untuk saling membantu dalam kelompoknya agar tugas dapat dikerjakan sebaik mungkin karena akan dipublikasikan. Seperti dinyatakan Yamin \& Maisah (2009, p.166) bahwa pekerjaan yang dipajangkan atau dipublikasikan diharapkan dapat memotivasi siswa untuk bekerja lebih baik dan menimbulkan inspirasi bagi siswa lain. Siswa dituntut untuk selalu bekerja sama dalam mempublikasikan tugas. Adanya penghargaan kelompok dalam langkah pembelajaran publikasi tugas melalui pembelajaran kooperatif tipe STAD menyebabkan kelompok akan terpacu menjadi lebih baik untuk bersama mencapai tujuan. Tujuan kelompok tidak akan tercapai tanpa adanya kerja sama setiap anggota kelompok, sehingga dengan bekerja kelompok dapat meningkatkan keterampilan sosial. Seperti diungkapkan Veenman, Kenter, \& Post (2000, p.281) "Teachers reported social skills, on-task behaviour and pupil self-esteem to improve as a result of having pupils work in groups". (Gurumelaporkan bahwa keterampilan sosial, perilaku, dan harga diri siswa dapat ditingkatkan sebagai hasil bekerja dalam kelompok). Sehingga, jika siswa terus dilatih bekerja dalam kelompok, maka diharapkan keterampilan sosial seperti solidaritas dan empati dapat ditumbuhkan sehingga siswa mudah bekerja sama dengan orang lain dengan kata lain keterampilan kerja sama siswa meningkat.

Publikasi tugas melalui pembelajaran kooperatif tipe STAD lebih berpengaruh daripada tanpa publikasi tugas melalui belajar kelompok terhadap kreativitas (berpikir kreatif) karena salah satu cara mengekspresikan kreativitas siswa yaitu dengan publikasi tugas. Ketika siswa tahu hasil pekerjaannya akan dipublikasikan, hal ini dapat memacu siswa secara optimal untuk belajar lebih baik dan lebih kreatif. Yamin \& Maisah (2009, p.166) mengemukakan bahwa sekolah merupakan sarana yang memberikan kebebasan pada guru dan siswa untuk mengembangkan kreativitas yang berkaitan dengan pembelajaran, seperti dinding, dan sudut kelas yang digunakan untuk memajangkan hasil kreativitas siswa. McDonald \& Hershman (2011, p.30) juga menyatakan pemanfaatan papan buletin kelas yang merupakan suatu cara mempublikasikan tugas siswa akan mendorong siswa meningkatkan daya pikir dan kreativitasnya. Jadi, publikasi tugas dapat melatih siswa lebih kreatif dan semangat belajar siswa menjadi semakin tinggi.

Adanya peer tutoring dalam publikasi tugas melalui pembelajaran koopertaif tipe STAD dapat mengasah kemampuan berpikir kreatif siswa. Huda (2014, p.23) menyatakan bahwa siswa yang dilatih untuk belajar strategistrategi interaksional cenderung memiliki cara berpikir dan belajar yang lebih kreatif. Dalam peer tutoring, siswa yang di-tutor dapat mengajukan pertanyaan pada siswa yang men-tutor yang dapat menunjukkan kemampuan mereka dalam mengkonstruksi pengetahuan dan mengemukakan pertanyaan yang bervariasi. Siswa yang men-tutor dapat meningkatkan kemampuan mereka dalam memberikan penjelasan dan menyelesaikan masalah dengan lebih terperinci, detil, dan efektif, bahkan dapat memunculkan pemikiran yang baru dan original sehingga meningkatkan kemampuan berpikir kreatif.

Strategi pembelajaran publikasi tugas melalui pembelajaran kooperatif tipe STAD lebih berpengaruh daripada tanpa publikasi tugas melalui pembelajaran kelompok terhadap prestasi belajar IPA siswa karena publikasi tugas adalah salah satu cara memberikan refleksi terhadap pekerjaan siswa, sehingga siswa 
merasa hasil karyanya dihargai. Evertson \& Emmer (2015, p.69) menyatakan cara dalam memberikan umpan balik kepada siswa adalah dengan memajangkan pekerjaannya. Itzkowitz (2013, p.431) menyatakan "This allowed the child to continue to value his own work well after its creation". (Memajangkan karya seni memungkinkan siswa untuk terus menghargai karyanya sendiri). Alexander (2008, p.277) juga menyatakan "The most powerful effect of documentation is that children gain satisfaction from their own efforts". (Efek paling kuat dari dokumentasi adalah siswa mendapatkan kepuasan dari usaha mereka sendiri). Dengan adanya umpan balik terhadap pekerjaan siswa melalui publikasi tugas, menjadikan siswa merasa usahanya dihargai dan dapat mendorong siswa untuk terus membaca, belajar, dan berdiskusi bahkan di luar jam pelajaran sehingga daya retensi siswa terhadap materi pembelajaran semakin meningkat.

Publikasi tugas dapat membangkitkan minat siswa untuk belajar. Kim, Park, \& Lee (2001, p.47) menyatakan: "When the learning environment includes the children's own creations, a connection between the topic and the environment is formed, thereby increasing the effectiveness of learning. Such displays encourage children to develop an interest in others' work and express opinions about each other's thoughts and creative expression.'Ini berarati ketika lingkungan belajar meliputi kreasi siswa sendiri, hubungan antara topik dan lingkungan terbentuk, sehingga meningkatkan efektivitas pembelajaran. Seperti memajangkan hasil karya, dapat mendorong siswa untuk mengembangkan minat pada pekerjaan orang lain dan mengekspresikan pendapat mereka tentang pengalaman mereka dan ekspresi kreatif. Jadi, publikasi tugas dapat menjadikan pembelajaran lebih efektif dan merangsang siswa untuk belajar. Chatib \& Fatimah (2014, p.17) menyatakan informasi pertama yang ditangkap oleh otak berupa gambar, visualisasi, atau display. Helm, Beneke, \& Steinheimer (1997, p.200) juga mengemukakan "Teachers who document are more often able to teach children through direct, firsthand, interactive experiences that enhance brain development". Publikasi tugas merupakan salah satu cara mendokumentasikan tugas siswa. Guru yang mendokumentasikan lebih sering, dapat memberikan pengajaran langsung dan pengalaman interaktif kepada siswa yang dapat meningkatkan perkembangan otak. Otak sangat membutuhkan display saat proses belajar ber- langsung. Bahkan, display menduduki urutan pertama yang memuaskan otak reptil siswa. Otak reptil adalah bagian paling belakang otak berupa batang yang menghubungkan bagian belakang otak dengan tulang belakang. Otak reptil yang membukakan pintu masuk arus informasi ke bagian otak berikutnya. Jika ada display, maka otak akan menyukainya. Sebaliknya jika tidak ada display, tidak akan menimbulkan minat belajar siswa dan siswa tidak akan memiliki selera belajar. Jika siswa sudah kehilangan selera belajar, maka proses berpikir siswa akan terganggu sehingga prestasi belajar siswa rendah.

Publikasi tugas dapat menjadikan kelas lebih menyenangkan dan dapat memberikan stimulus positif terhadap emosi siswa sehingga dapat meningkatkan prestasi belajar siswa. Salah satu cara mempercantik kelas adalah dengan memanfaatkan publikasi tugas dengan cara display disetiap jengkal lingkungan belajar terutama kelas. Chatib \& Fatimah (2014, p.48) mengemukakan "Dengan meletakkan suatu benda di dinding atau kaca, motivasi siswa untuk belajar dapat meningkat". Chatib \& Fatimah (2014, p.21) juga menyatakan "Lingkungan belajar sebagai lingkungan fisik harus memuaskan indera. Jika lingkungan belajar tidak ada gambar atau tulisan, mata kita tidak terpuaskan untuk belajar". Adanya tutorial antar siswa yang memiliki orientasi dan bahasa yang sama dalam publikasi tugas melalui pembelajaran kooperatif tipe STAD akan memberikan keuntungan baik pada siswa kelompok bawah maupun kelompok atas dalam meningkatkan kemampuan akademik sehingga prestasi belajar siswapun meningkat. Publikasi tugas melalui pembelajaran kooperatif tipe STAD adalah modifikasi dari pembelajaran kooperatif tipe STAD. Pembelajaran kooperatif tipe STAD terbukti dapat meningkatkan prestasi belajar siswa dibanyak penelitian. Hasil penelitian Wyk (2012) menunjukkan bahwa STAD dapat meningkatkan sikap positif, prestasi, dan motivasi siswa di pendidikan ekonomi. Wyk (2012, p.261) menyatakan "Results revealed that STAD compared to direct instruction promoted positive attitudes, showed better achievements and motivated students to learn in economics education". Hasil penelitian Adesoji \& Ibraheem (2009) bahwa STAD berpotensi meningkatkan hasil belajar kimia siswa di sekolah menengah. Adesoji \& Ibraheem (2009, p.23) "The treatment condition in this study i.e. STAD cooperative learning strategy had the potentials to improve students' learning outcome in 
secondary school chemistry". Hasil-hasil penelitian tersebut membuktikan bahwa pembelajaran kooperatif sangat efektif meningkatkan prestasi belajar siswa. Seperti dinyatakan Sanjaya (2009, p.250) menyatakan strategi pembelajaran kooperatif merupakan strategi yang cukup ampuh untuk meningkatkan prestasi akademik sekaligus kemampuan sosial. Stevens (2008, p.106) menyatakan "Cooperative learning processes increase student achievement through students interacting about the content in a social learning environment". (Pembelajaran kooperatif dapat meningkatkan prestasi melalui interaksi siswa tentang materi dalam lingkungan pembelajaran sosial). Dari penjelasan tersebut dapat disimpulkan bahwa pembelajaran kooperatif yang memberi peluang kepada siswa untuk bekerja sama dalam kelompok dalam mempelajari materi pembelajaran sangat efektif untuk meningkatkan prestasi belajar.

\section{SIMPULAN DAN SARAN}

\section{Simpulan}

Berdasarkan hasil analisis data dan pembahasan, dapat disimpulkan bahwa: (1) strategi pembelajaran publikasi tugas melalui pembelajaran kooperatif tipe STAD berpengaruh terhadap keterampilan kerja sama, kreativitas, dan prestasi belajar IPA; (2) terdapat perbedaan pengaruh antara strategi pembelajaran publikasi tugas melalui pembelajaran kooperatif tipe STAD dan tanpa publikasi tugas melalui belajar kelompok terhadap keterampilan kerja sama, kreativitas, dan prestasi belajar IPA dan (3) strategi pembelajaran publikasi tugas melalui pembelajaran kooperatif tipe STAD lebih berpengaruh dibandingkan tanpa publikasi tugas melalui belajar kelompok terhadap keterampilan kerja sama, kreativitas, dan prestasi belajar IPA siswa kelas VIII MTs Negeri I Lampung Tengah.

\section{Saran}

Berdasarkan simpulan, dapat disarankan kepada guru IPA untuk menjadikan publikasi tugas melalui pembelajaran kooperatif tipe STAD sebagai salah satu alternatif dalam memfariasikan pembelajaran yang digunakan dan kepada peneliti berikutnya disarankan untuk mengembangkan penelitian terkait publikasi tugas dengan cara pemajangan.

\section{DAFTAR PUSTAKA}

Adesoji, F. A., \& Ibraheem, T. L. (2009). Effects of student teams-achievement divisions strategy and mathematics knowlegde on learning outcomes in chemical kinetics. The Journal of International Social Research, 2, (6): 15-25.

Alexander, S. K. (2008). Windows on learning: documenting young children's work, by Judy Harris Helm, Sallee Beneke, \& Kathy Steinheimer. Catholic Education: A Journal of Inquiry and Practice, 12, (2): 276-278.

Boone, D. J. (2008). Young children's experience of visual displays of their artwork. Australian Art Education, 31, (2), 22-45.

Chatib, M., \& Fatimah, I. N. (2014). Kelasnya manusia memaksimalkan fungsi otak belajar dengan manajemen display kelas. Bandung: Kaifa.

Djamarah, S. B. (2012). Prestasi belajar dan kompetensi guru. Surabaya: Usaha Nasional.

Evertson, C. M., \& Emmer, E. T. (2015). Manajemen kelas untuk guru sekolah dasar edisi kedelapan. Jakarta: Kencana.

Gentry, R. (2012). Collaboration skills preservice teachers acquire in a responsive preparation program. Journal of Instructional Pedagogies, 8, 1-9.

Haycock, K. (2007). Collaboration: critical success factors for student learning. School Libraries Worldwide, 13, (1) 2535.

Helm, J. H., Beneke, S., \& Steinheimer, K. (1997). Documenting children's learning. Childhood education, 73, (4), 200-205.

Helm, J. H., Beneke, S., \& Steinheimer, K. (1998). Windows on learning: documenting young children's work early chilhood education series. New York and London: Teachers College Press.

Huda, M. (2014). Cooperative learning: metode, teknik, struktur, dan model penerapan. Yogyakarta: Pustaka Pelajar.

Itzkowitz, S. (2013). Valuing children's expression: afirst attempt at displaying preschool art in an early childhood centre. Mc Gill Journal Of Education, 48, (2): 425-434. 
Jayalekshmi, N. B., \& Raja, W. D. (2011). Does creativity impact scientific aptitude of school children? i-manager's Journal on Educational Psychology, 4, 33-38.

Johnson, D. W., Johnson, R. T., \& Smith, A. K. (1995). Cooperative learning. Minnesota: University Of Minnesota.

Johnson, D. W., Johnson, R. T., \& Smith, A. K. (1998). Maximizing instruction through cooperative learning. ASEE Prism ProQuest Educational Journals, 7, (6), 24-29.

Jollife, W. (2007). Cooperative learning in the classroom putting it into practice. London: Paul Chapman Publishing.

Joubert, M. M. (2007). The art of creative teaching: NACCCE and beyond. Creativity in Education, 17-34. (A. Craft, B. Jeffrey, \& M. Leibling, Eds.) London: Continuum.

Khan, G. N., \& Inamullah, H. M. (2011). Effect of student's team achievement division (STAD) on academic achievement of students. Asian Social Science, 7, (12), 211-215.

Kim, H., Park, E., \& Lee, J. (2001). “All done! take it home." then into a trashcan?: displaying and using children's art projects. Early Childhood Education Journal, 29, (1): 41-50.

Lord, T. R. (2001). 101 reasons for using cooperative learning in biology teaching. The American Biology Teacher, 63, 30-38.

Maker, C. J., Muammar, O., Serino, L., Kuang, C. C., Mohamed, A., \& Sak, U. (2006). The discover curriculum model: nurturing and enhancing creativity in all children. KEDI Journal of Educational Policy, 3, 2, 99-121.

McDonald, E. S., \& Hershman, D. M. (2011). Guru dan kelas cemerlang! menghidupkan dan meningkatkan pengajaran di dalam kelas. (Terjemahan Siti Mahyuni). Jakarta: PT Indeks. (Buku asli diterbitkan tahun 2010).

Munandar, U. (1999). Mengembangkan bakat dan kreativitas anak sekolah petunjuk bagi para guru dan orang tua. Jakarta: PT Gramedia Widia Sarana Indonesia.
Munandar, U. (2012). Pengembangan kreativitas anak berbakat. Jakarta: Rineka Cipta.

Rusman. (2012). Model-model pembelajaran mengembangkan profesional guru. Jakarta: Rajawali Pers.

Sanjaya, W. (2009). Strategi pembelajaran berorientasi standar proses pendidikan. Jakarta: Kencana.

Slameto. (2013). Utilizing ICT to improve influential cooperative learning toward student's achievement in Satya Wacana Christian University Salatiga 2012. International Journal of e-Education, eBusiness, e-Management and $e$ Learning, 3, (4): 330-332.

Slavin, R. E. (1995). Cooperative learning : theory, research, and practice. Boston: Allyn and Bacon.

Stevens, R. J. (2008). Cooperative learning and literacy instruction in middle level education. The teacher's role in implementing cooperative learning in the classroom, pp.92-107. (R. M. Gillies, A. Ashman, \& J. Terwel, Eds.) New York: Springer.

Sugiarto, A., \& Djukri, D. (2015). Pembelajaran berbasis SETS sebagai upaya meningkatkan kreativitas dalam pemecahan masalah pencemaran lingkungan. Jurnal Inovasi Pendidikan IPA, 1(1), 1-11.

Tiantong, M., \& Teemuangsai, S. (2013). Student team achievement division (STAD) technique through the moodle to enhance learning achievement. International Education Studies, 6, (4) : 85-92.

Veenman, S., Kenter, B., \& Post, K. (2000). Cooperative learning in Dutch primary classrooms. Educational Studies, 26, (3): 281-302.

Watson, R., \& Davis. (2010). Strategi pengajaran kreatif. Jakarta: Esensi Erlangga Group.

Wulandari, T., Fuady, A., \& Sumarwati. (2012). Peningkatan motivasi dan kemampuan menulis puisi melalui penerapan metode menulis berantai pada siswa sekolah menengah atas. BASASTRA Jurnal Penelitian Bahasa, Sastra Indonesia dan Pengajarannya, 1, 77-92. 
Jurnal Inovasi Pendidikan IPA, 2 (1), 2016 - 23

Dzawati Muttaqiyah, Indyah Sulistyo Arty

Wyk, M. M. (2012). The effects of the STADcooperative learning method on student achievement, attitude and motivation in economics education. Journal Social Science, 33, (2): 261-270.
Yamin, M., \& Maisah. (2009). Manajemen pembelajaran kelas strategi meningkatkan mutu pembelajaran. Jakarta: Gaung Persada Press. 